\title{
Tasks of IT Managers: Empirical Research Based on Job Advertisements in Germany
}

\author{
Bjarne Erik Roscher*1, Norbert G. Brink ${ }^{1, *}$ \\ ${ }^{1}$ Department of Economics and Business Administration, University of Latvia, Riga, Latvia
}

\begin{abstract}
.
Companies are more and more dependent on information technology (IT) and the buzzword digitization is present everywhere. Some companies are inventing new business models based on disruptive innovation supported by information technology. Others adapt these business models as followers. All these new business processes and underlying information technology need to be managed, serviced and supported by IT organizations to ensure business continuity. In the current research, job advertisements have been analyzed to investigate what task and responsibilities IT Managers are confronted with, when they enter a new position. The main findings are that still the main tasks seem to be managing of IT applications and IT infrastructure. Interestingly management of information and IT-trend and IT-technology scouting are underrepresented. This low representation is in harsh contrast to the fact that public press is talking about the age of Big Data, Deep Learning and artificial intelligence. These technologies arey are dependent on data and technology. Business-IT-Alignment and other IT management tasks are mentioned with a medium frequency in the findings.
\end{abstract}

Keywords: Chief Information Officer (CIO), IT Organization, Recruitment, CIO Role, Business-IT-Alignement

\section{Introduction: CIO Role and Tasks}

Synnott defined 1981 the role of the chief information officer (CIO) as the "senior executive responsible for establishing corporate information policy, standards, and management control over all corporate information resources" (Synnott et al. 1981)

This job title has been adapted also in other countries, among these Germany. Yet, this research indicates that this is mainly the case in larger enterprises while small and mid sized enterprises (SME) call their IT executives "IT Leiter", "IT Manager" or "IT Abteilungsleiter". Yet also US based research show that other job titles like "IT director", "SVP/VP IT" and "IT manager" are widely used (Tallon 2014).

Many studies have shown that the role of a CIO is essential for an organization:

A CIO can positively influence the company performance not only by fostering the IT efficiency, which means lowering cost and by this increase the profit but increase the IT effectivity through improved IT use (Durst 2008). 
Measures to drive IT efficiency are introducing tailored internal IT management systems (Schweda \& Schmidt 2014), efficient IT service management (ITSM) frameworks (Marrone \& Lutz 2011) and the right organizational setup (Hodgkinson 1992). An efficient budgeting and controlling process which ensures that investments in technology deliver the planned results (Chan et al. 2006) is essential. Measures to improve IT effectivity are underpinning business processes with appropriate information technology (Tallon 2014).

But ultimately a CIOs main task is to ensure Business-IT-Alignment (BITA). This results in strategic information technology initiatives driving business performance (Peppard 2010).

\section{Methodology of the empirical research}

To gain deeper insights into the CIO and IT Manager role, its tasks and scope, Job advertisements in Germany have been analyzed.

\subsection{Selection of Sources}

The search of the job market regarding open positions of CIOs and IT managers has been carried out by searching HR online portals and social networks which offer job advertisements. After searching on different portals, it was found that most job openings are present in several places. This led to the decision to focus on the following portals for final information gathering: www.LinkedIn.com and www.Indeed.com. A total of 87 job ads have been collected manually from 2 platforms (indeed.com and linkedin.com) on one single day (18.2.2020). All records have been copied and archived for further research.

The ads represent all job openings in Germany on a single day from these two platforms. Scope has been the upper IT management and digitization management jobs.

\subsection{Data cleansing}

Process of data cleansing: After manual proofreading, 4 records have been removed for the analysis as their job title did not correspond with the content or had been outdated or not complete. Additional four Datasets have been removed as the job title was Chief Digital Officer (CDO) and the tasks of these positions differed too much from those of IT managers and CIOs. The remaining $\mathrm{N}=79$ records have been analyzed with a structured content analysis.

\subsection{Codes}

These main Codes which have been used to cluster the information are:

- "Company" summarizes following Information: Company Name, Company info, Location, Benefits/Company Offers for employee, Number of employees in the company.

- "Job title" with 5 subcategories

- "Job information": This information is only given sparsely in the job openings: Information about the number of clients have been disclosed by 4 companies, Information about the report structure to the or respectively the collaboration model with the management has been disclosed in 10 cases. An overview over the area of responsibility was mentioned in 12 cases. 
- "Tasks": According to Krcmar (Krcmar 2015) the tasks for organizations can be clustered into 4 main areas

a) IT Management function based on the resource employee

b) Management of information based on the resource information

c) Management of information systems based on the resource IT application

d) Management of information- and communication technology based on the resource Infrastructure

This structure was used for this further research.

additional Codes not used for this research have been used:

Candidate "Profile"

a) formal training

b) Competences

c) Skills

\subsection{Coding rules}

Some codes on the first level as Tasks, Company info, Job information and Benefits/Company offers have partly been used several time per Job advertisements. This was used to analyze the structure of the records.

Others like Job title, Company name, Location only once, as well as subcategories of Task and Profile have only been used once per ad.

\subsection{Verification of Codes for Tasks}

Short Interviews have been conducted with 2 former CIOs which at the same time are active as visiting lecturers at University of applied Sciences in the area of Information Management and Business Informatics. Both from the region of Bavaria.

The gained data from the analysis of the Job advertisements, knowledge extracted from selected Literature and knowledge gained from the interviews have been combined to Task map of an IT Organization (see also Fig. 1). After sorting the results of the structured text analysis into the predefined categories and sub categories the remaining set of tasks have been used to define 3 new management tasks.

\section{Result of investigation}

\subsection{General findings}

The Records could be clustered into 4 Job title groups: Chief Information Officer / CIO (8), Chief, IT Leiter (37), IT Manager (23), other IT Manager Job titles (13). Some of the job titles have been combinations of the above which resulted in double counting.

The job advertisements have been published by companies in the following regions of Germany: Baden Württemberg (19), Bayern (11), Berlin (4), Brandenburg (1), Bremen (1), Hamburg (3), Hessen (8), Mecklenburg-Vorpommern (0), Niedersachsen (5), Nordrhein- 
Westfahlen (12), Rheinland Pfalz (5), Saarland (0), Sachsen (4), Sachsen Anhalt (3), Schleswig Hollstein (3), Thüringen (1).

\subsection{Remarks about structure and content of the Job advertisements with suggestions for further research.}

The Records $(\mathrm{N}=79)$ included the following structural categories:

High representation: Job title and Location (79), Tasks (88), Profile (84). Medium representation: Company info (51), Benefits/Company Offers (54). Low representation: Number of Locations (4), Clients (4), Employees in Company (15), Team size (24) and Reporting structure (10).

This implies that HR departments publishing the job ads are more interested to transport the requirements to the applicant than to inform about the future working environment. This might have a negative effect on number of received job applications as the applicant has to invest time to gather information by other media to see if he or she is interested into the future employer and position.

Job advertisements are a communication and marketing tool of organizations. It is the first contact point between employer and potential employee. As the job market for IT specialists is very tense, applicants have a wide choice of opportunities. Therefor employers should invest more time and effort to present the company to the future employee. Especially if one is looking at higher management positions where companies are looking for highly skilled and competent people which comparable high salaries and career levels this investment to find the best of the best should be intensified. Research indicates that both the appearance of a job add as well as the quality of the arguments has an effect on the number of applicants for an job opening [10].

Looking into Company benefits as arguments, it would be a future research area to evaluate if the offered benefits like Chocolate, company bicycle, coffee, massages and other nonmonetary offers are really relevant for applicants for management positions which typically have high salary and long working hours.

\subsection{Alignment of findings to literature models and new IT Management tasks.}

Krcmar developed based on findings of Wollnik (Wollnik 1988) and Szyperski und Winand (Szyperski \& Winand 1989) and his own research (Krcmar 1991) a 3 Level model of Information management

Wollniks 3 Levels of information management (IM) are well established which is also represented in the mentioning in the job openings for management of applications (52) and for management of infrastructure (66). Yet the management of information seems not to be widely seen as a task for IT managers by HR departments as they are only mentioned sparsely (6).

Interestingly the 4th task added in Krcmars model "Management Role of IT Organization" is not as clearly seen by employers and wide deviations in individual tasks are mentioned. 
The proposed subtasks from Krcmar are all mentioned in the set of records - yet with a medium to low frequency ( 7 to 37 ). All numbers are recalculated to percentages and are shown in Fig. 1.

\begin{tabular}{|c|c|c|c|c|c|}
\hline \multicolumn{6}{|c|}{$\begin{array}{l}\text { Management Role of IT Organization } \\
\text { (Resource: Employees) }\end{array}$} \\
\hline \multirow[b]{2}{*}{ Task: } & \multicolumn{5}{|c|}{ Job titles } \\
\hline & total & $\begin{array}{l}\text { CIO } \\
(8)\end{array}$ & $\begin{array}{l}\text { ITM } \\
(22)\end{array}$ & $\begin{array}{l}\text { ITL } \\
(37)\end{array}$ & $\begin{array}{l}\text { OIT } \\
\text { (12) }\end{array}$ \\
\hline IT Strategy & $39 \%$ & $38 \%$ & $27 \%$ & $59 \%$ & $33 \%$ \\
\hline IT Governance & $19 \%$ & $38 \%$ & $27 \%$ & $11 \%$ & $17 \%$ \\
\hline IT Processes & $47 \%$ & $63 \%$ & $41 \%$ & $41 \%$ & $42 \%$ \\
\hline IT Human Resources & $57 \%$ & $50 \%$ & $36 \%$ & $70 \%$ & $58 \%$ \\
\hline IT Controlling & $20 \%$ & $25 \%$ & $27 \%$ & $14 \%$ & $25 \%$ \\
\hline IT Security, Riskmngm. & $29 \%$ & $13 \%$ & $0 \%$ & $43 \%$ & $25 \%$ \\
\hline Data Security/Protection & $24 \%$ & $0 \%$ & $23 \%$ & $35 \%$ & $8 \%$ \\
\hline \multicolumn{6}{|c|}{ Additional Tasks according own research: } \\
\hline $\begin{array}{l}\text { Supplier Coordination / IT } \\
\text { Sourcing }\end{array}$ & $54 \%$ & $38 \%$ & $41 \%$ & $65 \%$ & $58 \%$ \\
\hline Budgeting & $33 \%$ & $25 \%$ & $36 \%$ & $32 \%$ & $33 \%$ \\
\hline IT Architecture & $51 \%$ & $50 \%$ & $32 \%$ & $70 \%$ & $33 \%$ \\
\hline Project Management & $58 \%$ & $25 \%$ & $50 \%$ & $68 \%$ & $58 \%$ \\
\hline $\begin{array}{l}\text { Consulting / Demand } \\
\text { Management (Top Level) }\end{array}$ & $38 \%$ & $38 \%$ & $27 \%$ & $54 \%$ & $33 \%$ \\
\hline
\end{tabular}
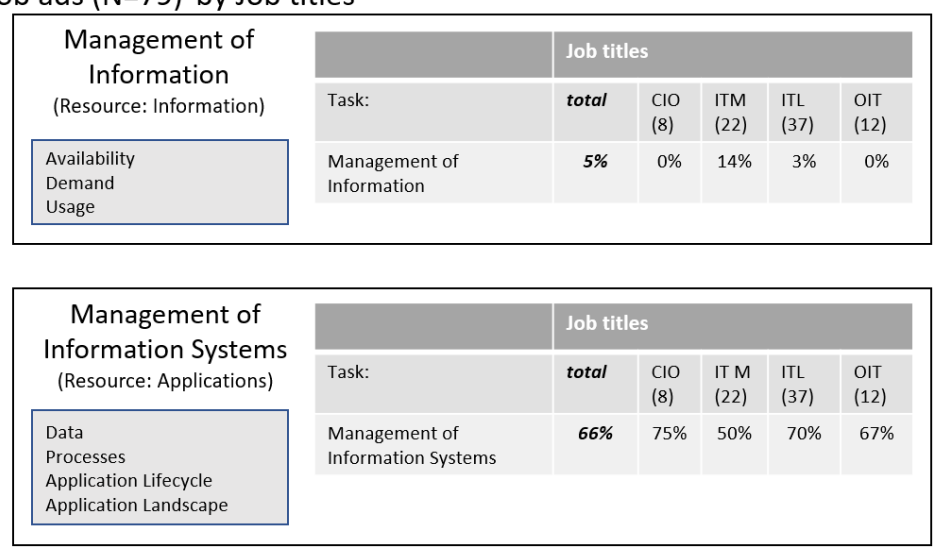

Fig. 1: Tasks of an IT Organization and representation in a sample of job ads $(N=79)$ sorted by job titles.

Yet further Management tasks are mentioned in the Job openings partly shown in Fig. 1 with different frequencies. These are clustered into tree new clusters:

Finance \& Administration: Supplier Coordination / IT Sourcing (43), Budgeting (26).

Innovation \& Architecture: IT Architecture (40), IT Trends and Technology (6).

Business-IT-Alignment: Project Management (46), Consulting / Demand Management on Management Level (30), Cooperation with others (14), IT effectivity (13)

Literature suggests that Project Management is a tool to align IT to business strategy (Miloševic, \& Srivannaboon 2006).

Furthermore, a category appears in the task section of the records:

- Leadership and Coaching of Employees (39)

Even if this sounds more like a skill it has for this analysis been addid to the IT Human Resource (7) counts. 


\section{References}

[1] Synnott, William R.; Gruber, William H. (1981): Information resource management. Opportunities and strategies for the 1980s. New York: Wiley.

[2] Tallon, Paul P. (2014): A Process-Oriented Perspective on the Alignment of Information Technology and Business Strategy. In: Journal of Management Information Systems 24 (3), S. 227-268.

[3] Durst, Michael (2008): Wertorientiertes Management von IT-Architekturen: Teubner.

[4] Schweda, Christian M.; Schmidt, Werner (2014): Leichtgewichtiges, unternehmensspezifisches IT-Management. In: HMD 51 (5), S. 606-615.

[5] Marrone, Mauricio; Kolbe, Lutz M. (2011): Impact of IT Service Management Frameworks on the IT Organization. In: Bus Inf Syst Eng 3 (1), S. 5-18.

[6] Hodgkinson, Stephen L. (1992): IT structures for the 1990s: organisation of IT functions in large companies. A survey. In: Information \& Management 22 (3), 161-175

[7] Chan, Y. E.; Sabherwal, R.; Thatcher, J. B. (2006): Antecedents and outcomes of strategic IS alignment. An empirical investigation. In: IEEE Trans. Eng. Manage. 53 (1), S. 27-47.

[8] Peppard, Joe (2010): Unlocking the Performance of the Chief Information Officer (CIO). In: California Management Review 52 (4), S. 73-99.

[9] Krcmar, Helmut (2015): Informationsmanagement. 6., überarb. Aufl. Berlin, Heidelberg: Springer Gabler.

[10] Jones, David A.; Shultz, Jonas W.; Chapman, Derek S. (2006): Recruiting Through Job Advertisements. The Effects of Cognitive Elaboration on Decision Making. In: Int J Selection \& Assessment 14 (2), S. 167-179.

[11] Wollnik, M. (1988): Ein Referenzmodell des Informationsmanagements. In: Information Management 3 (3), S. 34-43.

[12] Szyperski, Norbert; Winand, Udo (1989): Informationsmanagement und informationstechnische Perspektiven. In: Knut Bleicher, Eberhard Seidel und Dieter Wagner (Hg.): Organisation. Evolutionäre Interdependenzen von Kultur und Struktur der Unternehmung: Knut Bleicher zum 60. Geburtstag. Wiesbaden: Gabler, S. 133-150.

[13] Krcmar, Helmut (1991): Integration in der Wirtschaftsinformatik - Aspekte und Tendenzen. In: Integrierte Informationssysteme. Wiesbaden: Gabler Verlag (Schriften zur Unternehmens führung), S. 190.

[14] Miloševic, Dragan; Srivannaboon, Sabin (2006): A theoretical framework for aligning project management with business strategy. Paper presented at PMI® Research Conference: New Directions in Project Management, Montréal, Québec, Canada. Newtown Square, PA: Project Management Institute. 